\title{
A Three-Factor Model of Inclusive, Sustainable and Resilient Economic Development for Developing Countries
}

\author{
Samuel O. Okafor ${ }^{1}$, Kenneth Jegbefumwen ${ }^{2}$, Olisaemeka D. Maduka ${ }^{1} \&$ Ambrose C. Okeke ${ }^{1}$ \\ ${ }^{1}$ Department of Economics, NnamdiAzikiwe University, Awka, Anambra State, Nigeria. \\ ${ }^{2}$ Department of Economics, Novena University, Kwale, Delta State, Nigeria. \\ Correspondence: Samuel O. Okafor, Department of Economics, NnamdiAzikiwe University, P.M.B. 5025, Awka, \\ Anambra State, Nigeria.
}

Received:June 12, 2016

Accepted:June 27, 2016

Available online:July 7, 2016

doi:10.11114/aef.v3i4.1723

URL: http://dx.doi.org/10.11114/aef.v3i4.1723

\begin{abstract}
Nigeria had adopted various development plans in order to achieve MDGs.Achievement of MDGs is crucial to effective implementation of SDGs agenda aimed at fostering inclusive, sustainable and resilient economic development. In spite of these efforts, the Nigerian economy is still characterized by low capital formation, chronic unemployment, a large percentage of the population living on primary sector and negligible savings. Indeed, Nigeria's performance in MDGs was quite unimpressive. This is partly attributable to inappropriate human capital theory of economic growth on which these development plans were based. Therefore, this study focused on building a model of inclusive, sustainable and resilient economic development which would yield potent factors and describe activities that could link human capital investment with aggregate economic activities to induce economic development with full participation of target population. The study covered the period, 1981 - 2014. Data were sourced from Central Bank of Nigeria, National Bureau of Statistics and World Development Indicators. Data were analyzed using exploratory factor analysis technique. Study revealed that minimum wage, girl-child education and special intervention fund were factors which influenced the relationship among human capital, real GDP and economic development. It was concluded that the outcome of this study which is a three-factor model of inclusive, sustainable and resilient economic development is essentially a human capital theory of economic development capable of linking the different sectors of the economy. It was recommended, inter alia, that a dynamic employment policy would involve economic empowerment of women through job reservation in paid labour.
\end{abstract}

Keywords: three-factor model, inclusive, sustainable, resilient ,economic development, developing countries

\section{Introduction}

Sustainable, inclusive and resilient economic development which is a new course charted by world leaders at the United Nations Sustainable Development Summit on September 25, 2015 marked a shift fromMillennium Development Goals (MDGs) agenda to Sustainable Development Goals (SDGs) agenda (Clark, 2015).SDGs absorbed fromMDGs eight anti-poverty targets set to be achieved by 2015 . The achievement of these targets would certainly pave the way for the implementation of SDGs agenda. The new SDGs have broader policy implications for addressing the root causes of poverty and the universal need for development that works for all people.

Nigeria is still grappling to cope with the problems posed by MDGs. The performance of Nigeria in the implementation of MDGs agenda is unimpressive (Lawal, Obasaju\& Mathew, 2012). The effective implementation of MDGs agenda is crucial to the achievement of the objectives of SDGs agenda which would ultimately foster inclusive, sustainable and resilient economic development. Successive governments in Nigeria had adopted various development plans including VISION 2010, National Economic Empowerment and Development Strategy(NEEDS), 7-Point Agenda, VISION 20:2020, Subsidy Reinvestment Programme(SUREP) etc. within the framework of MDGs agenda to serve as driving force to achieve these laudable projects (Lawal et al., 2012). Despite these efforts, Nigeria has remained grossly underdeveloped. The Nigerian economy is still characterized by low capital formation, chronic unemployment, a large percentage of the population living on primary sector and negligible savings which were identified by Kumar and Sharma (2014) as common features of underdevelopment. This is a clear indication that the development plans were not effective for linking the different sectors of the Nigerian economy and ensuring full participation of the target 
population in the development process. For any development plan to be effective, it must be based on a theoretical framework which would establish interrelationships among human capital, aggregate economic activities (measured by real gross domestic product [real GDP]), and physical quality of life indices (PQLI) as proxies for economic development. This explains why human capital theory of economic growth, commonly applied for analysis of economic development, could not provide active constructs for designing effective development strategies. The inadequacy of human capital theory of economic growth for detailed analysis of economic development is glaring in Table 1 showing contractions in the relationship between GDP per capita (GDPPC) and human development indices (HDI) forNigeria and five other countries.

Table 1. GDPPC and HDI Compared Between Nigria and Five African Countries For the Period 2014

\begin{tabular}{llcc}
\hline Level & Country & GDPPC & HDI \\
\hline High & Algeria & 1.6 & .737 \\
High & Tunisia & 1.2 & .722 \\
& & & \\
Medium & South Africa & 0.0 & .666 \\
Medium & Ghana & 1.4 & .579 \\
Low & Angola & 1.8 & .532 \\
Low & Nigeria & 3.5 & .514 \\
\hline
\end{tabular}

Knoema, 2015 and UNDP, 2015

Table 1 shows that Nigeria had greater GDPPC and yet lower HDI than Algeria, Tunisia, South Africa, Ghana and Angola. Okafor, Jegbefumwen and Ike (2016) had also found human capital theory of economic growth grossly inadequate for a detailed analysis of impact of human capital investment on economic development.

Therefore, there is a need to develop a theory which can establish interrelationships among human capital, real GDP and economic development. Only a human capital theory of economic development can yield constructs to serve as active variables to induce human capital and real GDP to contribute to economic development. Efforts were focused on a detailed analysis of interrelationships among human capital, real GDP and economic development indicators in order to identify latent factors to constitute major constructs of a new theory on the basis of which a comprehensive development plan could be devised for achieving inclusive, sustainable and resilient economic development for Nigeria and indeed, developing countries.

The study was undertaken with the broad objective of building a model which would yield active policy instruments for facilitating the achievement of inclusive, sustainable and resilient economic development for Nigeria and indeed, other developing economies. Specific objectives are to :(1) Identify the factors influencing the relationships among human capital investment, growth and economic development (2)Determine the constellation of active variables of the factors which contribute significantly to the inter-correlations among human capital investment, growth and economic development.

The study revolved around the answering of the following research questions: (1) What are the factors which influenced the relationship among human capital investment, growth and development in Nigeria? (2) What is the constellation of active variables of the factors which contribute significantly to the inter-correlations among human capital investment, growth and economic development in Nigeria?

The results of this study were considered significant as they would be found useful by policy-makers in developing countries for reviewing the strategies of their development plans and for setting new guidelines to ensure effective implementation of these plans for the actualization of SDGs.

\section{Review of Related Literature}

This section deals with the review of related literature. The review has been discussed under the following subheadings.

- Theoretical literature review

- Empirical literature review

- Summary of review

\subsection{Theoretical Literature Review}

\subsubsection{Theories on Economic Growth}

Endogenous Growth Theory- Endogenous growth theory states that a high saving rate leads to a high growth rate. Endogenous growth theory lays emphasis on different growth opportunities in physical capital and knowledge capital. 
This theory is predicated on the premise that there are substantial external returns to capital; the major assumption is that better technology is produced as a by product of capital investment. It specifically assumes that technology is proportional to the level of capital per worker in the economy overall, and that technology is labour-augmenting (Dornbusch, Fischer, \& Startz, 2011). This theory has applicability in the Nigerian situation where there is generally low saving and low technology base

Solow Growth Model-This model is an extension of Harrod-Domar model with the addition of the second factor, labour, and the introduction of a third independent variable, technology. Solow growth model is based on the assumption of diminishing returns to labour and capital separately and constant returns to both factors jointly. Technological progress became the residual factor explaining long-term growth,and its level was assumed to be exogenously determined, that is, independently of all other factors. Solow model is expressed in the form:

$\mathrm{Y}=\mathrm{K}^{\alpha}(\mathrm{AL}) 1-\alpha$ where $\mathrm{Y}$ is the gross domestic product, $\mathrm{K}$ is the stock of capital (which may include human capital as well as physical capital). L is labour and A is the productivity of labour which grows at exogenous rate ( Solow, 1956).

The implications of Solow growth model are three fold. Firstly, nations are demarcated on the basis of their income. Secondly, they are distinguished on the basis of their population sizes. Thirdly, countries are demarcated on the basis of the level of technological advancement. Thus, it follows as a corollary that a model of inclusive and sustainable economic development would work differently for MDCs and LDCs. Solow's growth model has relevance for the present study in the sense that it has contributed variables such as real GDP and human capital (capital and recurrent expenditures on health and education) which have been included in the analysis.

\subsubsection{Theories on Economic Development}

Neoclassical Counter-Revolution Model-This theory adopts three approaches, namely, free market approach, the new political economy approach and the market-friendly approach. This theory focuses on promoting free market, eliminating government-imposed distortions associated with protectionism, subsides and public ownership (Johnson, 1971; Little, 1982; Lal, 1983 ; Bauer, 1984). In essence, the theory attributes underdevelopment to domestic issues arising from poor resource allocation, government-induced price distortions and corruption (Meier, 2000). The implication of this theory is that government interferences in economic activities, dominance of public enterprises, subsidy regime, price control, protectionism and corruption are characteristics of underdevelopment. The theory is adequate for a detailed analysis of the Nigerian economy as a developing country with its manifestation of almost all features of underdevelopment outlined in this theory.

Theory of coordination failure-This theory states that market may fail to achieve coordination among contemporary activities. According to the theory contemporaries exist when returns on one investment depends on the presence or the size of other investment. In their contribution to the further development of this theory Hoff and Stiglitz (2000), revealed that coordination failure could lead the market to an equilibrium outcome inferior that subsequently pushes the economy into underdevelopment equilibrium. The major implication of this theory is that poor coordination of economic activities often leads economies to attain equilibrium output at less than full employment. The theory is valid in the Nigerian situation where poor management of resources has been responsible for the slow pace of economic development as measured by extreme poverty in the midst of plenty.

\subsubsection{Theory on Human Capital}

Human capital theory of economic growth-This theory states that education raises productivity and efficiency of workers by increasing the level of their cognitive skills. In other words, investment in education develops the cognitive abilities of individual by combining innate abilities with investment in human beings. Human capital is a manifestation of human abilities or potentials which are useful, on their own, in production process (Schultz, 1962). To Becker (1993), human capital is needed for direct application in production process. This theory has strong link with the present study which has viewed investment in education at primary, secondary and tertiary levels as a dimension of human capital investment.

Human capital theory has provided the theoretical base for the present study. Human capital theory which emphasizes the role of acquired knowledge/skill in the attainment of higher productivity and output has come close to theories of economic development that place high premium on physical qualities of life. The preferred choice of human capital theory as a theoretical base of the study is reinforced further by the existence of proxies for human capital components in the constructs of human capital theory. To buttress this point, literacy rate is a common indicator of education and economic development while life expectancy and mortality rate are both common indicators of health and economic development.

\subsection{Empirical Literature Review}

Schultz (1992) embarked on review of empirical role of education and human capital in economic development. He 
reported that human capital is an important determinant of modern economic growth and a critical factor in explaining the convergence in growth across countries. The policy implication of his finding is that wage differentials should be taken into account as both an indicator of private payoff to educational investments in a national labour market and a criterion in setting public priorities to foster development and often to promote a more equal distribution of personal income. This study is linked to the present study by way of considering unemployment, literacy rate, real GDP and GDP per capita as important variables included in the factor model for this study.

Benhabib and Spiegel (1994) studied the role of human capital in economic development using cross-country data. Study covered the period, 1965 - 1985. They applied OLS involving multiple regression technique for the analysis of data. Study revealed that human capital entered insignificantly in explaining growth rates in these economies. The study had limitation of not focusing on the problem it set out to solve. It was intended to determine the role of human capital in economic development but ended up reporting a finding on the role of human capital on economic growth. Notwithstanding, the policy implication is clear- that human capital should be given due consideration whenever economic growth is planned. It is relevant to the present study which considers human capital as an instrument for achieving inclusive development.

Gundlach (1996) carried out a study titled 'Human capital and economic development'. His study was a review of empirical studies on the role of human capital in economic development. He had reported serious methodological issues which tended to undermine the reliability of their results. He had recommended that further studies in this area should include such variables as quality of education, experience of work force, health status and nutritional status of the population. This study is relevant to the present study which has adopted holistic approach through the inclusion of disaggregated human capital, real GDP, GDP per capita, physical quality of life indices in a factor model used for this study.

Wawire and Nafukho (2006), in their article titled 'Investment in human capital through institutions of higher education for the revival of Kenya's economy' examined the role of human capital and physical capital in the revival of the Kenyan economy. Study covered the period, 1972-2000. Data were analyzed using OLS revolving around multiple regression technique. Study revealed that human capital and physical capital did not contribute significantly to economic growth in Kenya. The limitation of this study is the application of multiple regression for the analysis of data from a small sample. This finding has policy implication for the government to adopt measures in higher educational institutions for revamping real economic growth through increased investment in human resource development. The study has relevance for the present study as it has yielded suitable reference materials for a detailed analysis.

Awe and Ajayi (2010) studied human capital investment- economic growth nexus in Nigeria. Study covered the period, 1975 - 2005. They employed OLS involving co-integration and error correction mechanism. Study revealed the existence of unidirectional relationship between human capital investment and economic growth in Nigeria. The major limitation of this study is the failure to indicate which of the variables cause the effect on the other. The policy implication of this finding is that, for sustained growth, human capital should be developed. This study is relevant to the present study as it has created insight into the problem which the present study set out to solve.

Adelakun (2011) studied the effect of human capital development on economic growth in Nigeria. The study spanned across 1985-2009. Study employed multiple regression technique for the analysis of data. Result indicates that there was a positive significant relationship between human capital development and economic growth in Nigeria. This result may not be accurate as analysis of data from small sample with multiple regression technique leads generally to misleading inferences. Nevertheless, the finding has policy implication for the government to strive toward achieving higher growth through mobilization of human resources.

Ejere (2011) undertook a study to establish the status of human capital formation as a catalyst for national development in Nigeria. Study covered the period, 1999-2010. Data were analyzed using qualitative technique which was essentially situational. Study revealed that human capital was critical in the development process. Focusing on national development, rather than economic development is a major drawback of this study. Notwithstanding, the finding has policy implication for the government to adopt skill-and- knowledge approach for actualizing vision 2020.

Sunde and Vischer (2012) studied the effect of human capital on economic growth. The study spanned across 1965 2005. Data were sourced from UN population division for 94 countries. Data were analyzed using Penn World Tables version 6.3. Study revealed that human capital had positive significant effect on economic growth and that human capital had stronger effect on population with higher life expectancy and better environmental conditions. The policy implication of the finding is that improved quality of education and health would enhance economic development.

Ogujiuba (2013) investigated the impact of human capital formation on economic growth in Nigeria. Study spanned across 1970-2010.Study employed OLS technique for the analysis of data. Results indicate that investment in human capital in the form of education and capacity building at primary and secondary levels contributed significantly to 
economic growth in Nigeria while capital expenditure on education did not. The findings of the study have policy implication for the government to restructure the country's education system in order to ensure high quality and functional education capable of enhancing economic growth.

Baah-Boateng (2013) studied the role of human capital development in economic transformation of Africa. Study employed a sample of 104 countries including both developed and developing economies. Data were analyzed using Spearman's and Pair wise correlation technique. Study revealed that there was a significant relationship between education and structural transformation of the economy. This finding has policy implication for African countries to enhance their human capital base through increased public investment in education in the areas of teacher motivation and provision of adequate teaching and learning materials. The result of this study was found useful for comparing with the findings of the present study.

Mehrara and Musai (2013) carried out a study to determine the nature of relationship between economic growth and human capital development in developing countries. The study covered the period, 1970-2010. Data were analyzed using panel unit root tests and panel co-integration test. Study revealed a strong causality from investment and economic growth to education, with education not having any significant effects on GDP and investment in short- and long- run. This finding has policy implication for developing countries to promote practice-oriented training for students particularly in technical disciplines and matching education system to the needs of the labour market. This study has provided suitable reference materials for the present study.

Eigbiremolen and Anaduaka (2014) carried out a study to determine the impact of human capital development and economic growth in Nigeria. The study covered the period, 1999-2012. Study employed OLS techniques including ADF and Johansen co-integration tests for analysis of data. Findings indicate that: (1) Human capital development impacted positively on output level (2) There was inelastic relationship between human capital development and output level. The drawback of this study is the application of regression technique to data from a sample as small as 14 . The findings have policy implication for the government to development human capital in order to achieve sustainable development in Nigeria. The study has relevance for the present study as it has yielded results which constitute a priori expectation for the present study.

Shobande, Odeleye and Olunkwa (2014) investigated the impact of human capital investment on economic development in Nigeria. The study spanned across 1970-2011. Study employed OLS techniques including ADF, Johansen co-integration and ECM for the analysis of data. The study revealed that there was short-run negative relationship between economic development and human capital investment in Nigeria. This study is relevant to the present study as it has provided a suitable framework for a detailed analysis of the role of human capital investment in economic development. Policy implication is that in developing a model for inclusive and sustainable economic development the role of human capital in economic development must be given due consideration.

Torruam and Abur (2014) carried out a study on the impact of human capital development on economic growth in Nigeria. The study spanned across 1997-2012. Data were analyzed using co-integration test. Result indicates that there was bidirectional causality running from economic growth to human capital development and from total expenditure on education to total expenditure on health in Nigeria. The limitation of the study is the failure to create an insight into the magnitude and direction of impact of human capital investment on economic growth. Notwithstanding, it is relevant to the present study as its finding has provided a basis for comparing with findings of the present study.

Torabi and Abbasi-Shavazi (2015) studied the impact of women's human capital on growth in the Middle East and North Africa. Study employed a range of data sources. A detailed analysis of data was carried out to determine the degree of association between women's human capital and economic growth. Study revealed that there was a positive association between the two. A limitation of this study is that the technique for data analysis was not clearly stated. However, the finding of this study has policy implication for ameliorating women's health and education situation in some countries with low income levels and strong patriarchal and stratified gender roles. The result of this study is useful for comparing with the outcome of the present study.

Pelinescu (2015) studied the impact of human capital on economic growth. Study spanned across 2000-2012. Panel data from Eurostat database were used for the study. Study employed descriptive statistics and pooled least square techniques for the analysis of data. Results indicate that: (1) There was positive significant relationship between GDP per capita and innovative capacity of human capital and qualification of employees (2) There was negative relationship between education expenditure in GDP and GDP per capita. The weakness of this study is the use of extremely small sample which could limit its generalizability. However, it has relevance to the present study as it has provided a base for constructing the model for inclusive and sustainable economic development. Policy implication of findings for government is the need to fund education and health adequately in order to induce economic growth.

Okafor, Jegbefumwen and Ike (2016) studied the role of human capital investment in inclusive and sustainable 
economic development in Nigeria. Study covered the period, 1982-2014. Study employed OLS including ADF test and multiple regression techniques for the analysis of data. Results indicate that: (1) Government recurrent expenditure on education, government capital expenditure on education and health impacted positively on GDP per capita (2) All components of human capital investments except government recurrent expenditure on health had positive significant impact on infant mortality rate (3) Infant mortality rate was more reliable than GDP per capita as an index of economic development. The main limitation of this study is use of human capital theory of economic growth for the analysis of economic development. Notwithstanding, it has provided the desired stimulus for the present study. Policy implication of findings to government is that a comprehensive health policy with attractive welfare package should be evolved as incentive to halt continuing human capital flight from health sector.

\subsection{Summary of Review}

Theoretical literature review has revealed that only nuances in meanings of economic growth and economic development exist. This slight differences soon fade away when the implications of the definitions of growth and development are viewed within the context of human capital theory but it is the very inequality in growth of countries which has brought to fore the fact that countries with equal growth rates may differ in their levels of economic development. Thus, it becomes reasonable to argue that neither human capital theory, nor theories of economic growth nor theories of economic development, acting separately, could provide a strong base for developing a model for inclusive, sustainable and resilient economic development. A concatenation of major constructs of all three theories has become necessary in an effort to build a dynamic model.

Empirical literature has revealed that studies in this area are not entirely new. Sustained research interest in this area spanning across mid $20^{\text {th }}$ century to the present century are an indication that search is continuing in order to find key variables that would link human capital with aggregate economic activities, as measured by real GDP, to stimulate economic development. The review further revealed that out of the 16 studies in empirical literature, nine studies were focused on impact of human capital investment on economic growth while seven studies were focused on impact of human capital investment on economic development.

Out of the nine studies which focused on impact of human capital investment on economic growth, only two studies including Wawire and Nafukho (2006) and Mehrara and Musai (2013) had reported that human capital investment did not impact positively on growth. Out of the seven studies which focused on the impact of human capital investment on economic development, only three studies, Baah-Boateng (2013), Shobande et al., (2014) and Okafor et al., (2016) provided conclusive evidences of critical role of human capital investment in economic development. Inconclusive evidences on impact of human capital investment on economic development were provided by Schultz (1992), Benhabib and Spiegel (1994), Gundlach (1996) and Ejere (2011). Analytical lapses of this nature in studies on growth and development are due to inadequacy of human capital theory of economic growth for a detailed analysis of economic development.Human capital theory of economic growth which does not recognize the nuances in meanings of growth and development cannot prove effective for analyzing data on economic development.This has provided a prior justification for this study aimed at building a model of economic development that would take into cognizance the differences between growth and development.

\section{Method and Procedure}

\subsection{The Data}

The data for the study were collected from Central Bank of Nigeria (CBN), National Bureau of Statistics(NBS) and World Development Indicators(WDI). Data were collected from 1981 - 2014. The variables included in the study are components of human capital investment, real GDP and physical quality of life indices.

\subsection{Empirical Model}

As stated earlier, the broad objective of this study was the building of a model which would yield active policy instruments for facilitating the achievement of inclusive, sustainable and resilient economic development for Nigeria and indeed, other developing economies. The model used for this study was adopted with modification from Mankiw, Romer and Weil (1992), Adelakun (2011), and Okafor, Jegbefumwen and Ike (2016). This has been presented below.

$\mathrm{IMR}=\mathrm{f}$ (TFR, GFR, CDR, CBR, GMR, OPV, DPT, MSV, WFP, RMC, POV, UNN, LIT, LEX, GPC, CEE, CHE, REE, RHE, GDP)

Where IMR is infant mortality rate; TFR is total fertility rate; GFR is general fertility rate; CDR is crude death rate; CBR is crude birth rate; GMR is general mortality rate; OPV is oral polio vaccine; DPT is Diphtheria vaccine; MSV is measles vaccine; WFP is family planning (women); RMC is reported malaria cases; POV is poverty rate; UNN is unemployment rate; LIT is literacy rate; LEX is life expectancy; GPC is GDP per capita; CEE is capital education expenditure; CHE is capital health expenditure; REE is recurrent education expenditure; RHE is recurrent health 
expenditure; GDP is real gross domestic product.

\subsection{Factor Model Specification}

The study employed common factor model. The a prior justification for the choice of common factor model was the application of Solow model augmented by Mankiw et al. (1992) which expresses a linear functional relationship among $\mathrm{Y}, \mathrm{K}$, and $\mathrm{H}$; where $\mathrm{Y}$ is real GDP, $\mathrm{K}$ is physical capital and $\mathrm{H}$ is human capital. In line with this model,the present study has also adopted a model which expresses a functional relationship among IMR, TFR, GFR, CDR, CBR, GMR, OPV, DPT, MSV, WFP, RMC, POV, UNN, LIT, LEX, GPC, CEE, CHE, REE, RHE, GDP. Common factor model is considered to be suitable when the variables are assumed to a linear function of a set of latent variables (Tucker, Koopman \& Linn,1969; Ford, MacCallum\&Tait, 1986). The underlying assumption of this model is that the variance can be divided into common and unique components with the unique variance being further divided into specific and random error variance (Rummel, 1970).

There are 21 variables -IMR(CRN), TFR, GFR, CDR, CBR, GMR, OPV, DPT, MSV, WFP, RMC, POV, UNN, LIT, LEX, GPC, CEE, CHE, REE, RHE and GDP. Factor analysis model requires that the variables included in the analysis should be linearly related to each other. Scatterplots of pairs of variables conformed to linearity. The factor model used for this study was developed by Cornish (Cornish, 2007). The model has been expressed algebraically in the form:

$$
\mathrm{X}_{\mathrm{i}}=\alpha_{\mathrm{i} 1} \mathrm{~F}_{1}+\alpha_{\mathrm{i} 2} \mathrm{~F}_{2}+\ldots+\alpha_{\mathrm{im}} \mathrm{F}_{\mathrm{m}}+\mathrm{e}_{\mathrm{i}}
$$

Suppose there are $\mathrm{p}$ variables $\mathrm{X}_{1}, \mathrm{X}_{2}, \ldots \mathrm{Xp}$ measured on a sample of $\mathrm{n}$ subjects, variable $\mathrm{I}$ is a linear combination of $\mathrm{m}$ factors $F_{1}, F_{2}, \ldots, F m$ and $m<p$, where ais are the factor loadings for variable $i$ and ei is that part of variable xi that cannot be explained by the factors.

Since there are 21 variables, the rule of thumb requires that only one-third of the total number of variables could be extracted as factors. Therefore, the factor analysis model has been written in the form:

$$
\mathrm{IMR}=\alpha \mathrm{i}_{1} \mathrm{~F}_{1}+\alpha \mathrm{i}_{2} \mathrm{~F}_{2}+\alpha \mathrm{i}_{3} \mathrm{~F}_{3}+\alpha \mathrm{i}_{4} \mathrm{~F}_{4}+\alpha \mathrm{i}_{5} \mathrm{~F}_{5}+\alpha \mathrm{i}_{6} \mathrm{~F}_{6}+\alpha \mathrm{i}_{7} \mathrm{~F}_{7}+\mathrm{ei}
$$

where $\alpha \mathrm{i}_{1}$ is the factor loading of factor 1

$\alpha \mathrm{i}_{2}$ is the factor loading of factor 2

$\alpha \mathrm{i}_{3}$ is the factor loading of factor 3

$\alpha \mathrm{i}_{4}$ is the factor loading of factor 4

$\alpha \mathrm{i}_{5}$ is the factor loading of factor 5

$\alpha \mathrm{i}_{6}$ is the factor loading of factor 6

$\alpha i_{7}$ is the factor loading of factor 7

ei is the part of criterion variable IMR that cannot be explained by that factor.

\subsection{Validation Technique}

To determine the adequacy of factor analysis for the present study, Kaiser-Meyer-Olkin (KMO) statistic and Bartlett's test of sphericity (Chi-Square) were computed. KMO statistic was used to ascertain whether or not the factors were comprised of sufficient numbers of variables while Chi-Square was used to ascertain whether or not the variables were sufficiently correlated. KMO value should be greater than 0.7 to justify the application of factor analysis while Chi-Square value should be significant at 0.05 confidence interval to infer that the variables were sufficiently correlated (Cornish, 2007).

KMO and Bartlett's Test

\begin{tabular}{lcc}
\hline Kaiser-Meyer-Olkin & Measure of Sampling Adequacy & .747 \\
Bartlett's Test of & Approx Chi-Square & 1295.696 \\
Sphericity & df & 210 \\
& sig. & .000 \\
\hline
\end{tabular}

As has been presented, computed KMO statistic value is greater thanthe criterion KMO while Chi-square value is significant at 0.000 . These results imply that the factors were comprised of sufficient numbers of variables and that the variables were sufficiently correlated. This has justified the use of factor analysis in the study. 


\subsection{Eigenvalues for Determination of Number of Factors}

Cornish(2007) had suggested that to determine the number of factors to be extracted, say $\mathrm{m}$, the number of eigenvalues should be divided by 1 to obtain $\mathrm{m}$. The eigenvalues have been presented in Table 2 .

Table 2. Eigenvalues for Determination of Number of Factors

\begin{tabular}{|c|c|c|c|c|c|c|}
\hline \multicolumn{7}{|c|}{ Total Variance Explained } \\
\hline \multicolumn{4}{|c|}{ Initial Eigenvalues } & \multicolumn{3}{|c|}{ Extraction sums of squared loadings } \\
\hline Component & Total & $\%$ of Variance & Cumulative $\%$ & Total & $\%$ of Variance & Cumulative $\%$ \\
\hline 1 & 13.083 & 62.299 & 62.299 & 13.083 & 62.299 & 62.299 \\
\hline 2 & 2.549 & 12.140 & 74.438 & 2.549 & 12.140 & 74.438 \\
\hline 3 & 1.542 & 7.345 & 81.783 & 1.542 & 7.345 & 81.783 \\
\hline 4 & .960 & 4.573 & 86.356 & & & \\
\hline 5 & .911 & 4.336 & 90.693 & & & \\
\hline 6 & .652 & 3.107 & 93.800 & & & \\
\hline 7 & .361 & 1.720 & 95.520 & & & \\
\hline 8 & .235 & 1.121 & 96.641 & & & \\
\hline 9 & .221 & 1.050 & 97.691 & & & \\
\hline 10 & .137 & .652 & 98.342 & & & \\
\hline 11 & .114 & .544 & 98.887 & & & \\
\hline 12 & .086 & .412 & 99.298 & & & \\
\hline 13 & .051 & .245 & 99.543 & & & \\
\hline 14 & .042 & .199 & 99.742 & & & \\
\hline 15 & .019 & .090 & 99.831 & & & \\
\hline 16 & .013 & .061 & 99.892 & & & \\
\hline 17 & .010 & .050 & 99.942 & & & \\
\hline 18 & .008 & .037 & 99.979 & & & \\
\hline 19 & .002 & .012 & 99.991 & & & \\
\hline 20 & .001 & .007 & 99.998 & & & \\
\hline 21 & .000 & .002 & 100.000 & & & \\
\hline
\end{tabular}

Extraction Method: Principal Component Analysis

As can be seen, the number of eigenvalues equals 3 , when divided by 1 yields 3 . It follows therefore, that only three factors were extracted.

\subsection{Evaluation Criteria}

Study employed factor analysis technique for analyzing the data. The main focus of factor analysis was to determine the nature of factor structure of human capital investment-economic growth-economic development nexus in Nigeria. The principal axes method was employed for the factorization of the inter-correlation matrix. This method is also known as the method of principal factor solution.

To keep the number of independent dimensions to the essential minimum, extraction of factors was restricted to only those values of correlation coefficients equal to or greater than unity. The conservative rule of thumb requires that no attempt should be made to take decision on the significance of unrotated loadings, e.g., as obtained from centroid method or the method of principal axes (Nunnally,1967). Thus, following this principle, the Varimax rotation of the matrix was carried out.

By rotating the factors slightly in a clockwise direction, the strength of the relationship between the factors and the variables clustered near each other was increased (Pophan, 1967; Kline, 1994). Rotation improves the meaningfulness, reliability and reproducibility of factors (Weiss,1976; Ford et al, 1986). Interpretation of results was based on the new values of factor loadings obtained through the use of 'Orthogonal Rotation' formula expressed in the form of $\mathrm{X} 1=\mathrm{X} \cos \theta$ $+Y \sin \theta$. Factor loadings which were equal to or greater than \pm .4 were considered to be significant. Ford et al. (1986) had suggested the inclusion of factor loading $\geq .4$. Factor loadings of the criterion variable were given for all factors disregarding the level of significance so as to ascertain whether or not the factors represented correlates of IMR. The process of factor extraction was discontinued when the number of factors $(\mathrm{m}=$ number of eigenvalues $3 / 1$, i.e.,3)(Cornish,2007). Extracting too many factors may present undesirable error variance but extracting too few factors might leave out valuable common variance (Yong \& Pearce, 2013). 


\section{Results}

\subsection{Correlation Matrix}

Inter-correlations among IMR and 20 independent variables have been presented in Table 3.

Table 3. Correlation Matrix $(21 \times 21)$ Among IMR(CRN) and Independent Variables

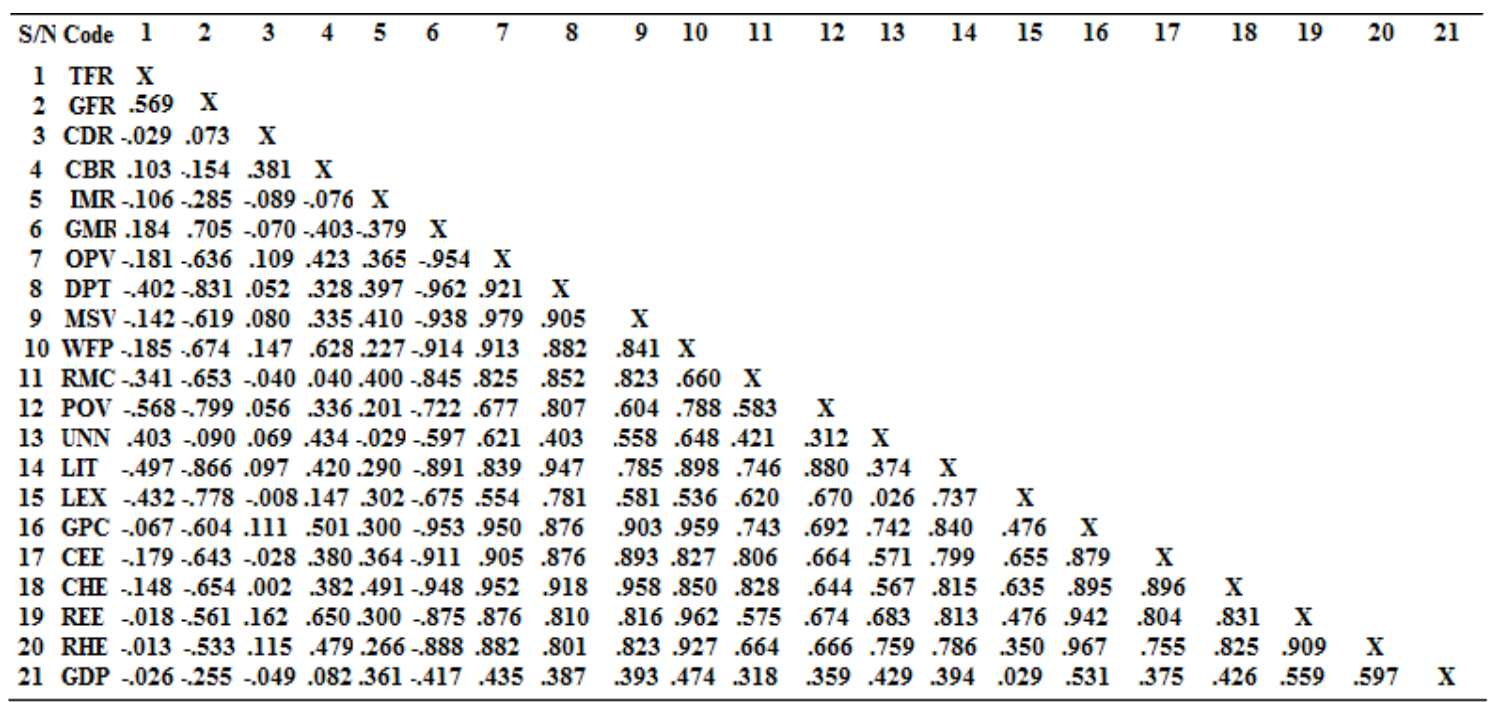

Table 3 shows zero-order inter-correlations arranged in a landscape.

\subsection{Factor Structure of Human Capital Investment-Economic Growth-Economic Development Nexus}

The factor structure of human capital investment-economic growth-economic development nexus has been presented in Tables 4 and 5 to facilitate the extraction of factors lying concealed in the interrelationships among the criterion variable and independent variables.

Table 4. Principal Axes (Original) Factor Structure of Human Capital Investment-Economic Growth-Economic Development Nexus(N=34)

\begin{tabular}{cccccc}
\hline S/N & Variable Codes & Factor 1 & Factor 2 & Factor 3 & $\mathrm{~h}^{2}$ \\
1 & TFR & -.259 & .788 & .275 & .764 \\
2 & GFR & -.753 & .515 & .104 & .843 \\
3 & CDR & .081 & .233 & -.630 & .458 \\
4 & CBR & .448 & .462 & -.589 & .762 \\
5 & IMR & .382 & -.211 & .535 & .477 \\
6 & GMR & -.981 & -.020 & -.049 & .964 \\
7 & OPV & .964 & .093 & .056 & .941 \\
8 & DPT & .967 & -.217 & -.010 & .982 \\
9 & MSV & .929 & .050 & .137 & .885 \\
10 & WFP & .953 & .165 & -.176 & .966 \\
11 & RMC & .821 & -.226 & .250 & .788 \\
12 & POV & .797 & -.300 & -.254 & .790 \\
13 & UNN & .588 & .689 & .099 & .830 \\
14 & LIT & .931 & -.232 & -.188 & .955 \\
15 & LEX & .666 & -.534 & -.119 & .743 \\
16 & GPC & .961 & .244 & .023 & .983 \\
17 & CEE & .916 & -.001 & .104 & .849 \\
18 & CHE & .945 & .022 & .169 & .922 \\
19 & REE & .911 & .300 & .092 & .929 \\
20 & RHE & .901 & .322 & .035 & .916 \\
21 & GDP & .486 & .239 & .365 & .427 \\
\hline
\end{tabular}

Table 4 presents the original principle component factor matrix. The last column reveals the communalities $\left(\mathrm{h}^{2}\right)$. On the whole, factor analysis led to the extraction of three factors, in conformity with the criterion stated earlier. 
4.3 Varimax (Rotated) Factor Structure of Human Capital Investment-Economic Growth-Economic Development Nexus

Table 5. (Rotated) Factor Matrix for Huamn Capital Investment-Economic Growth-Economic Development(N=34)

\begin{tabular}{|c|c|c|c|c|c|c|}
\hline $\mathrm{S} / \mathrm{N}$ & Variable Codes & Factor 1 & Factor 2 & Factor 3 & $h^{2}$ & $\mathrm{U}^{2}=\left(1-\mathrm{h}^{2}\right)$ \\
\hline 1 & TFR & .230 & -.843 & .027 & .764 & .236 \\
\hline 2 & GFR & -.358 & -.843 & .069 & .843 & .157 \\
\hline 3 & CDR & .042 & .045 & .674 & .458 & .542 \\
\hline 4 & CBR & .473 & .051 & .732 & .762 & .238 \\
\hline 5 & IMR & .338 & .215 & -.563 & .477 & .523 \\
\hline 6 & GMR & -.846 & -.498 & .007 & .964 & .036 \\
\hline 7 & OPV & .870 & .429 & .012 & .941 & .059 \\
\hline 8 & DPT & .706 & .695 & -.040 & .982 & .018 \\
\hline 9 & MSV & .838 & .420 & -.080 & .885 & .115 \\
\hline 10 & WFP & .844 & .434 & .255 & .966 & .034 \\
\hline 11 & $\mathrm{RMC}$ & .636 & .546 & -.290 & .788 & .212 \\
\hline 12 & POV & .467 & .741 & .151 & .790 & .210 \\
\hline 13 & UNN & .856 & -.256 & .180 & .830 & .170 \\
\hline 14 & LIT & .628 & .740 & .118 & .955 & .045 \\
\hline 15 & LEX & .272 & .815 & -.065 & .743 & .257 \\
\hline 16 & GPC & .934 & .318 & .099 & .983 & .017 \\
\hline 17 & CEE & .794 & .463 & -.068 & .849 & .151 \\
\hline 18 & $\mathrm{CHE}$ & .844 & .442 & -.119 & .922 & .078 \\
\hline 19 & REE & .894 & .281 & .224 & .929 & .071 \\
\hline 20 & RHE & .925 & .220 & .114 & .916 & .084 \\
\hline 21 & GDP & .608 & -.034 & -.236 & .427 & .573 \\
\hline \multirow{3}{*}{\multicolumn{2}{|c|}{$\begin{array}{l}\text { Sum of Squares } \\
\% \text { of Total Variance } \\
\% \text { of Common Variance }\end{array}$}} & 9.969 & 5.515 & 1.690 & & \\
\hline & & 47.472 & 26.263 & 8.048 & & \\
\hline & & 47.472 & 26.263 & 8.048 & & \\
\hline
\end{tabular}

Table 5 presents the rotated Varimax factor matrix along with the communalities and uniqueness of the variables. The total variance of any variable comprises of common variance $\left(h^{2}\right)$ as well as specific variance and error variance. Now, since it is usually difficult to separate specific variance from error variance, both are always combined and denoted by unique variance $\left(\mathrm{u}^{2}\right)$. This has been revealed in the last column of this table. At the end of each column of the factor, the eigenvalues, i.e., percentages of total variance and common variance contributed by the factor were entered.

\subsection{Factors Linking Human capital Investment to Growth and Economic Development.}

In order to identify factors 1,2 , and 3 which have crystallized from data analysis, Table 5 was split further into three sub-tables. This was done to facilitate discussion on significant factor loading of each of the factors.

\subsubsection{Factor 1}

Significant factor loadings on Factor 1are shown in Table 5.1 for sake of convenience of discussion of results. As has been explained earlier, the Varimax rotation of the original factor matrix involving the dimension of human capital investment, growth and development were carried out. The Varimax version was presented in descending order in Table 5.1 .

Table 5.1 Varimax Factor 1

\begin{tabular}{cllc}
\hline S/N & Description of Variable & Code & Factor Loading \\
\hline 16 & GDP per capita & GPC & .934 \\
20 & Recurrent health expenditure & RHE & .925 \\
19 & Recurrent education expenditure & REE & .894 \\
7 & Oral polio vaccine & OPV & .870 \\
13 & Unemployment rate & UNN & .856 \\
6 & General mortality rate & GMR & -.846 \\
10 & Family planning (women) & WFP & .844 \\
18 & Capital health expenditure & CHE & .844 \\
9 & Measles vaccine & MSV & .838 \\
17 & Capital education expenditure & CEE & .794 \\
8 & Diphtheria vaccine & DPT & .706 \\
11 & Reported malaria cases & RMC & .636 \\
14 & Literacy rate & LIT & .628 \\
21 & Real gross domestic product & GDP & .608 \\
4 & Crude birth rate & CBR & .473 \\
12 & Poverty rate & POV & .467 \\
5 & Infant mortality rate & IMR(CRN) & .338 \\
\hline
\end{tabular}


Table 5.1 shows that Factor 1 had its highest loading on GPC. Highest positive significant loading on GPC, in conjunction with very high positive significant loadings on RHE and REE brings Factor 1 close to personal income component of national income account. Positive significant loadings on OPV, UNN, WFP, CHE, MSV, CEE, DPT, RMC, LIT, GDP, CBR and POV imply that as Factor 1 increases these variables also increase, and vice-versa. This is only a rational expectation. Therefore, it is reasonable to suggest that Factor 1 cannot be anything other than 'minimum wage'. This is confirmed further by negative significant loading on GMR as increase in minimum wage leads to a rise in standard of living which in turn causes a reduction in GMR. Positive, though nonsignificant loading on IMR, and positive significant loading on UNN imply that a country which frequently adjusts its minimum wage upwards, in disregard for wage-productivity gap, is usually characterized by high unemployment rate and low level of economic development. Of particular interest are the positive signs on factor loadings on GPC and IMR. This would serve as an indication that GPC is not a reliable index of inclusive, sustainable and resilient economic development.

The common factor variance accounted for by minimum wage was 47.47 per cent which is 47.47 per cent of the total variance explained by the three factors.

Certain independent variables have combined in specific constellation to form Factor 1(minimum wage). Constellation of independent variables of minimum wage with very high factor loadings $\geq .800$ are GPC, RHE, REE, OPV, UNN, GMR, WFP, CHE and MSV. These have been considered to be strong predictors of minimum wage. Recall that Kline (1994) had stated that factor loadings are same as regression weight. Viewed thus, this constellation of variables constitute a group of activities that impact on minimum wage.

\subsubsection{Factor 2}

Significant loadings on Factor 2 have been presented in descending order in Table 5.2 to facilitate discussion of results.

Table 5.2 Varimax Factor 2

\begin{tabular}{clll}
\hline S/N & Description of Variable & Code & Factor loading \\
\hline 1 & Total fertility rate & TFR & -.843 \\
2 & General fertility rate & GFR & -.843 \\
15 & Life expectancy & LEX & .815 \\
12 & Poverty rate & POV & .741 \\
14 & Literacy rate & LIT & .740 \\
8 & Diphtheria vaccine & DPT & .695 \\
11 & Reported malaria cases & RMC & .546 \\
6 & General mortality rate & GMR & -.498 \\
17 & Capital education expenditure & CEE & .463 \\
18 & Capital health expenditure & CHE & .442 \\
10 & Family planning (women) & WFP & .434 \\
7 & Oral polio vaccine & OPV & .429 \\
9 & Measles vaccine & MSV & .420 \\
5 & Infant mortality rate & IMR(CRN) & .215 \\
\hline
\end{tabular}

As can be seen in Table 5.2, Factor 2 had equal negative significant loadings on TFR and GFR . Since TFR and GFR relate to the total number of women within the reproductive span, 15-49, Factor 2 is gender biased. Negative significant loadings of Factor 2 on TFR and GFR imply that as Factor 2 rises TFR and GFR fall and vice-versa. It follows, therefore, that delayed marriages caused a sharp decline in TFR and GFR. Education, being a veritable tool for averting child marriage and empowering the women, comes closest to Factor 2. Thus, Factor 2 has been aptly identified as girl-child education. Positive significant loadings on LEX, POV, LIT, DPT, RMC,CEE, CHE, WFP, OPV and MSV imply that these variables increase as more female children are educated. However, there is a need to address a contentious issue which has emerged with the positive significant loading on POV. The plausible explanation for this is that the education of the girl-child not only exerts added pressure on the over stretched budgets of households but worse still constitutes a leakage to the country's productive base as most educated women in Nigeria by accident or design still end up in the kitchen. Negative significant loading on GMR implies that the education of the girl-child leads generally to a decline in GMR. There is no gainsaying that education equips the would-be mothers to live positive and healthy life and inculcate positive and healthy living habits to members of their families. Positive though nonsignificant loading on IMR implies that the education of a girl-child not accompanied by women empowerment would slow down the pace of inclusive, sustainable and resilient economic development.

The extent of common factor variance contributed by Factor 2 was 26.26 per cent which is 26.26 per cent of the total variance explained by the three.

Constellation of independent variables of girl-child education with very high factor loading $\geq .800$ include TFR, GFR and LEX. These are strong predictors of girl-child education. 


\subsubsection{Factor 3}

Significant loadings on Factor 3 have been presented in Table 5.3 to facilitate discussion of results.

Table 5.3 Varimax Factor 3

\begin{tabular}{clcc}
\hline $\mathrm{S} / \mathrm{N}$ & Description of Variable & Code & Factor loading \\
\hline 4 & Crude birth rate & $\mathrm{CBR}$ & .732 \\
3 & Crude death rate & $\mathrm{CDR}$ & .674 \\
5 & Infant mortality rate & IMR(CRN) & -.563 \\
\hline
\end{tabular}

Table 5.3 shows that Factor 3 had its highest loading on CBR followed by CDR . Positive significant loading on CBR implies that as Factor 3 increases CBR also increases. Two factors which can induce a rise in CBR are economic empowerment and improved medical services. But economic empowerment and improved medical services can only induce a rise in CBR without necessarily causing a corresponding increase in CDR. Therefore, it is a reasonable deduction that only special intervention fund, e.g., donations, grants and aids from international agencies channeled specifically toward prevention of polio, mother-to-child HIV transmission, maternal mortality and infant mortality have the propensity to increase CBR and reduce IMR without necessarily reducing CDR. Incidentally, rising CDR was due to the operation of Malthusian principle. Okafor (2001) had observed the operation of Malthusian principle in the Nigerian situation where natural calamities such as communal clashes, diseases, pipeline explosions, etc. act as check against rapid population growth. Negative significant loading on IMR implies that a country which records high rate of performance in the use of special intervention funds are incline to achieve inclusive, sustainable and resilient economic development. Therefore, Factor 3 has been identified as special intervention fund. The common factor variance accounted for by special intervention fund was 8.05 per cent which is 8.05 per cent of the total variance explained by the three factors.

\subsubsection{Diagrammatic Representation of Factors}

For at a glance appreciation, the factors have been presented diagrammatically in Figures 1, 2 and 3.

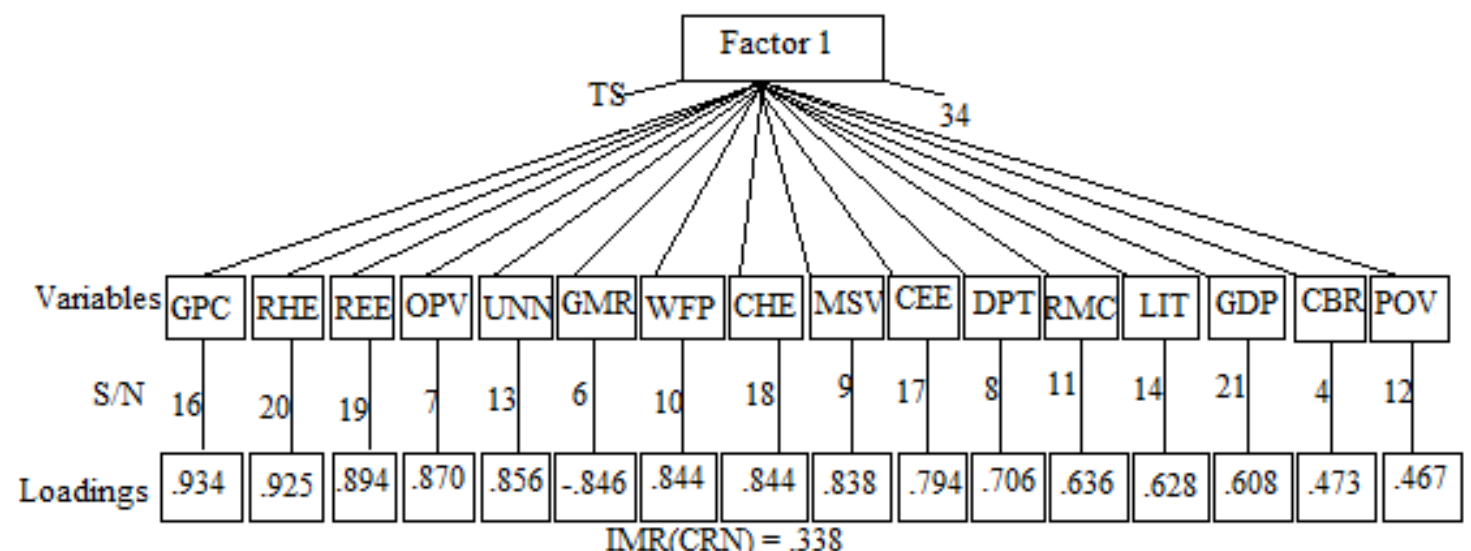

Figure 1. Factor 1: Minimum Wage

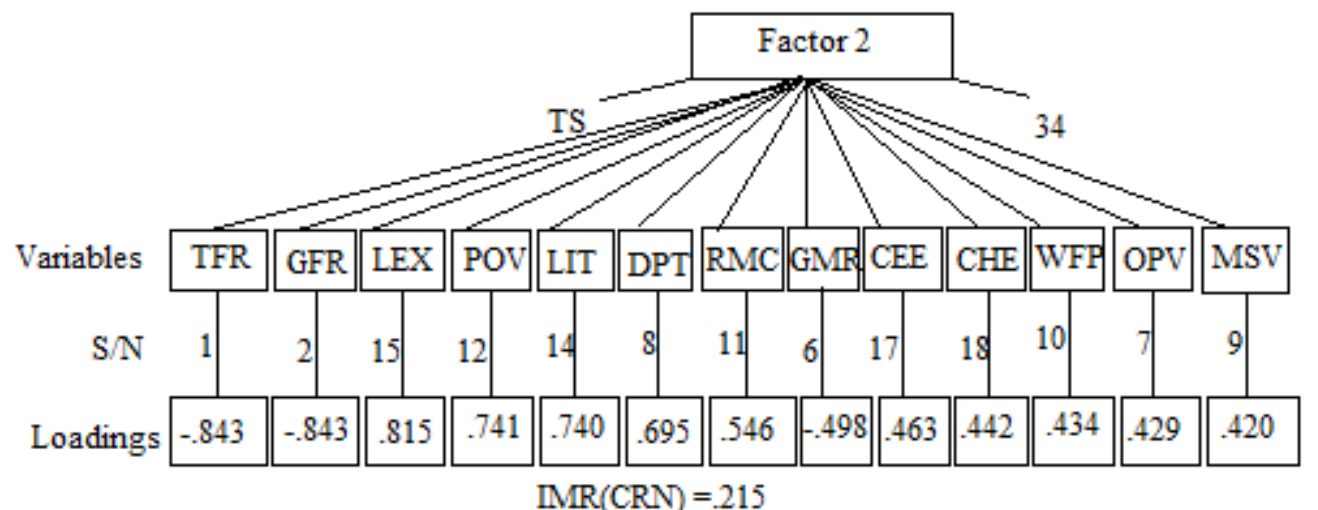

Figure 2. Factor 2: Girl-Child Education 


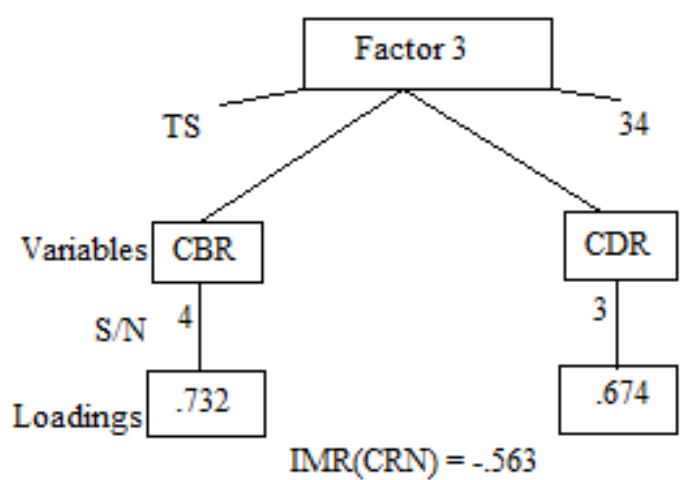

Figure 3. Factor 3: Special Intervention Fund

Model for Inclusive, Sustainable and Resilient Economic Development:

$$
\mathrm{IMR}=.338 \mathrm{MNWAGE}+.215 \mathrm{GIRLED}-.563 \mathrm{SPFUND}+.1822
$$

where MNWAGE is minimum wage; GIRLED is girl-child education; SPFUND is special intervention fund; 18.22 per cent of inter-correlations among the variables was left unexplained.

\subsection{Summary of Major Findings}

Major findings which have crystallized from this study include the following:

1. Minimum wage, girl-child education and special intervention fund were potent factors which influenced the relationship among human capital investment, growth and development in Nigeria.

2. GPC, RHE, REE, OPV, UNN, GMR, WFP, CHE, MSV, TFR, GFR and LEX combined in a specific constellation of active variables of inclusive, sustainable and resilient economic development.

3. IMR was a reliable index of inclusive, sustainable and resilient economic development.

\section{Discussion of Findings and Conclusions}

\subsection{Discussion of Findings}

An important finding of the study is that minimum wage, girl-child education and special intervention fund were potent factors which influenced the relationship among human capital investment, economic growth and economic development in Nigeria. This finding has not come as a surprise. Minimum wage has remained one of the most contentious issues in Nigeria. Trade unions in Nigeria often demand upward review of minimum wage through prolonged strike. Upward reviews of minimum wage without due consideration to labour productivity have often been conceded to by government to pacify the striking workers. The consequence of this is that the widening wage-productivity gap leads to declining output and rising general price level which often end in stagnation and job losses. Elgin and Kuzubas (2013) had also reported a finding which indicates that wage-productivity gap usually leads to unemployment. Also, the emergence of girl-child education as a potent factor which tended to inhibit economic development in Nigeria has come much in expectation. Certain communities in Nigeria still perceive that the place of the woman is the kitchen and as a result they consider girl-child education as unnecessary. It is therefore, not surprising that girl-child education tended toward inhibiting economic development as the educated girl-child is miserably confined to the kitchen and not economically empowered. Joshi (2012) had also reported that in Bangladesh, social and cultural practices which restrict female mobility may allow women to receive reproductive health services and have fewer children but may also require her to work at home rather than engage in salaried labour. With respect to special intervention fund, its positive contribution to economic development is the result of its direct impact on infant mortality. Most developing countries including Nigeria have relied heavily on international goodwill and co-operation for reproductive health services and disease control in specific areas such as polio eradication, prevention of mother-tochild HIV transmission, reduction of maternal and infant mortality, etc. Accordingly, UNDP (2015) had outlined the SDG in reproductive health services and disease control on specific areas including (1) to reduce child mortality (2) improve maternal health and combat HIV/AIDS, malaria and other diseases. Ajiye (2014) had cast aspersion on Nigeria's capacity to achieve MDG due to its limited resources and high level of corruption. Notwithstanding, National Bureau of Statistics (2014) had reported a sharp decline in infant mortality rate from 2.99 in 2005 to 0.13 in 2014.

Another major finding of the study is that GPC, RHE, REE, OPV, UNN, GMR, WFP, CHE, MSV, TFR, GFR and LEX combined in specific constellation of active variables of inclusive, sustainable and resilient economic development. This has come much in expectation. GDP per capita is being increasingly used by modern economists as proxy for 
economic development. Shobande et al. (2014) used GDP per capita as proxy for economic development in their model. Human capital theory of economic growth has established a strong link between human capital and economic growth (Schultz, 1962; Becker, 1993). Investment in human capital leads generally to improvement in quality of life which in essence is economic development. In the same vein GPC, RHE, REE, OPV, UNN, GMR, WFP, CHE, MSV, TFR, GFR, and LEX are all measures of physical quality of life and indicators of economic development. Obviously, this marks a point of departure from the conventional treatment of human capital theory of economic growth as an auxiliary theory of economic growth to a more general treatment of human capital theory as theory of economic development.

Moreover, there is the finding that IMR was a reliable index of inclusive, sustainable and resilient economic development. This finding has come as expected. The adequacy of human capital theory for a detailed analysis of economic development is what has placed a high premium on infant mortality as reliable index of economic development. Okafor et al. (2016) had found infant mortality rate to be more reliable than GDP per capita as index for economic development. The choice of GDP per capita as index of economic development was a product of application of human capital theory of economic growth to the analysis of economic development, a procedure which fail to recognize the nuances in meanings of growth and development. There is no gainsaying that the three-factor model of inclusive, sustainable and resilient economic development with infant mortality rate as criterion variable is essentially a human capital theory of economic development.

\subsection{Conclusions}

The major generalization that has been educed from this study is that three factors, namely, minimum wage, girl-child education and special intervention fund influenced the relationship among human capital investment, growth and development in Nigeria. Through proper minimum wage legislation, functional girl-child education and high rate of productive utilization of special intervention fund, it is possible to establish linkages among aggregate economic activities in different sectors of the economy with the direct involvement of the target population in order to induce inclusive, sustainable and resilient economic development. This is simply the postulate of the three-factor model of inclusive, sustainable and resilient economic development with infant mortality as its criterion variable. Undeniably, the use of factor analytic approach in this study is a clear departure from economists' frequent use of econometric technique for data analysis, and provides a relieve from the monotony of econometric technique which pervades the economic literature. To establish the validity of factor model, it is suggested that further studies using econometric technique for data analysis be carried out to determine the extent to which minimum wage, girl-child education and special intervention fund contribute to growth and development. However, it is important to state that the fundamental differences among developing countries on education, health and workforce employment could limit the generalizability of the result of this study which has considered Nigeria as a typical case.

This model relies heavily on a more dynamic human capital theory of economic development, a by-product of this study, for the analysis of the data. It is therefore in this context that the three-factor model of inclusive, sustainable and resilient economic development and human capital theory of economic development are considered as twin products of this analysis with the following far- reaching policy implications: (1) There is a need to take into cognizance the tendency of minimum wage in Nigeria to raise unemployment rate and inhibit economic development. Certainly, an appropriate wage policy should aim at minimum wage legislation which would reduce drastically wage-productivity gap in order to ensure maximum national income, low general price level and high rate of employment. (2) Considering that girl-child education tended toward raising poverty, and inhibiting economic development, a dynamic employment policy would involve economic empowerment of women through job reservation in paid labour. (3) The result that special intervention fund induced economic development has created a need for developing countries to seek greater international co-operation in areas of reproductive health services and disease control. The involvement of international agencies in these areas have often proved productive as project monitoring by these agencies often avert embezzlement of special intervention fund. (4) With the emergence of GPC, RHE, REE, OPV, UNN, GMR,WFP, CHE, MSV,TFR, GFR and LEX as active variables affecting inclusive, sustainable and resilient economic development, it has become necessary to consider them as major constructs of this model and veritable policy instruments for achieving inclusive, sustainable and resilient economic development. (5) The high reliability of infant mortality rate as an index of economic development imposes on policy-makers in Nigeria and other developing countries the need to embark on elaborate development plan aimed at reducing drastically infant mortality rate.

\section{Acknowledgements}

We are grateful to Our Lord Jesus Christ for His inspiration and guidance. We thank MrsIfeoma J. Okafor (wife of the principal researcher) for her technical support throughout the duration of this study.

\section{Reference}

Adelakun, O. J. (2011). Human capital development and economic growth in Nigeria .European Journal ofBusiness and 
Management, 3(9), 29-38.

Ajiye, S. S. (2014). Achievements of millennium development goals in Nigeria: A critical examination. International Affairs and Global strategy, 25, 24-36.

Awe, A. A., \& Ajayi, S. O. (2010).The nexus between human capital investment and economic growth in Nigeria.Pakistan Journal of Social Sciences, 7(1), 1-7. http://dx.doi.org/10.3923/pjssci.2010.1.7

Baah-Boateng, W. (2013). Human capital development: The case of education as a vehicle for Africa's economic transformation. Legon Journal of International Affairs and Diplomacy, 7(1), 31-55. http://globallabormarkets.org/wp-content/uploads/2013/12/Human-Capital.pdf

Bauer, P. T. (1984). Reality and rhetoric: Studies in economics of development.London: Weidenfield\& Nicolson.

Becker, G. (1993). Human capital: A theoretical and empirical analysis with special reference to education. Chicago: The University of Chicago Press.http://dx.doi.org/10.7208/chicago/9780226041223.001.0001

Benhabib, J., \& Spiegel, M. M. (1994). The role of human capital in economic development : Evidence from aggregate cross-country data. Journal of Monetary Economics, 34, 143-173.http://dx.doi.org/10.1016/0304-3932(94)90047-7

Clark, H. (2015). Sustainable development goals (SDGs). http//:www.undp.org/content/undp/en/home/sdgoverview/post-2015-development-agenda.html

Cornish, R. (2007). Statistics: Factor analysis. Mathematics learning support centre 1-3.

Dornbusch, R., Fischer, S., \& Startz, R. (2011). Macroeconomics ( 11th ed.). Singapore: McGraw-Hill.

Eigbiremolen, G. O., \&Anaduaka, U. S. (2014). Human capital development and economic growth: The The Nigeria experience. International Journal of Academic Research in Business and Social Sciences, 4(4), 25-35. http://dx.doi.org/10.6007/IJARBSS/v4-14/749

Ejere, E. S. I. (2011). Human capital formation as catalyst for national development: Nigeria in perspective.International Business and Management, 2(2), 98-104.

Elgin, C., \& Kuzubas, T. U. (2013).Wage-productivity gap in OECD economies. Economics: The Open-Access, 7, 1-21. http://dx.doi.org/10.5018/economics-ejournal.ja.2013-21.http://dx.doi.org/10.5018/economics-ejournal.ja.2013-21

Ford, J. K., MacCallum, R. C., \& Tait, M. (1986). The application of exploratory factor analysis in applied psychology: A critical review and analysis. Personnel psychology, 8(2), 291-314.http://dx.doi.org/10.1111/j.1744-6570.1986.tb00583.x

Gundlach, E. (1996). human capital and economic development: A macroeconomic assessment. Working Paper, Kieler Arbeitspapiere, 778, 1-43. http://hdl.handle.net/10419/920

Hoff, K., \& Stiglitz, J. E. (2000). Modern economy theory and development. InG.M. Meier \& J.E. Stiglitz (Eds.) Frontiers of development economics: The future in perspective, 389-485. Washington, D.C.: World Bank/Oxford University Press

Johnson, H. (1971). A word to the third world: A western economist's frank advice. Encounter, 37, 3-10.

Joshi, S. (2012). Reproductive health and economic development: What connections should we focus on? Research Brief. http://www.prb.org/pdf12/poppov-economicdevelopment-reproductivehealth-women.pdf

Kline, P. (1994). An easy guide to factor analysis. London: Routledge.

Knoema. (2015). GDP per capita ranking 2015/ data and charts. https://knoema.com/sijweyg/gdp-per-capita-ranking-2015-data-and-charts

Kumar, A., \& Sharma, U. (2014). Traditional vs. modern measures of economic development: A theoretical analysis. International Journal of Scientific Footprints, 2(1), 94-101.

Lal, D. (1983). The poverty of development economics. London: Institute of Economic Affairs.

Lawal, A. I., Obasaju, B., \& Rotimi, E. M. (2012). Towards achieving millennium development goals goals (MDGs) in Nigeria: Prospects and challenges. Journal of Economics and Sustainable Development, 3(9), 74-82.

Little, I. M. D. (1982).Economic development: Theory, policy and international relations. New York: Basic Books.

Mankiw, G., Romer, D., \& Weil, D. (1992).A contribution to the empirics of economic growth. QuarterlyJournal of Economics, 107, 407 - 437.http://dx.doi.org/10.2307/2118477

Mehrara, S., \& Musai, M. (2013).The relationship between economic growth and human capital in developing countries.International Letters of Social and Humanistic Sciences, 5, 55-62. http:// dx.doi.org/ 10.18052/www.scipress.com/ILSHS.5.55 
Meier, G. M. (2000). The old generation of development economists and the new. In G.M. Meier \& J.E. Stiglitz (Eds.) Frontiers of development economics: The future in perspective, 13-50. Washington, D.C.: World Bank/Oxford University Press.

NBS (2014).National Bureau of Statistics.

Nunnally, J. C. (1967). Psychometric Theory. New York: McGraw Hill.

Ogujiuba, K. (2013). The impact of human capital formation on economic growth in Nigeria.J, Economics, 4(2), $121-132$

Okafor, S .O., Jegbefumwen, K., \& Ike. A. N. (2016). Human capital investment for inclusive and sustainable economic development :The Nigerian experience. Journal of Economics, Finance andManagement Sciences, 11(2 March), 107-121.

Okafor, S. O. (2001). Population growth and distribution in Nigeria. In L.N. Eze (Ed.) Issues and Trendsin Social Science, 136-152.

Pelinescu, E. (2015). The impact of human capital on economic growth.Procedia Economics and Finance, 22, 184-190. http://dx.doi.org/10.1016/S2212-5671(15)00258-0

Popham, W. J. (1967). Educational Statistics.New York: Harper \& Row Publishers.

Rummel, R. J. (1970). Applied Factor analysis.Evanston. IL: Northwestern University Press.

Schultz, T. P. (1992). The role of education and human capital in economic development :An empiricalassessment. Center Discussion Paper, 670.Economic Growth Center, Yale University.

Schultz, T. W. (1962). Reflexions on Investment in man.Journal of Political Economy, 70(5), 1-8. http://dx.doi.org/10.1086/258723

Shobande, O. A., Odeleye, A. T., \&Olunkwa, N.C. (2014). Human capital investment and economic development: The Nigerian experience. World Journal of Social Science, 1(2), 107-115. http://dx.doi.org/10.5430/wjss.vln2p107

Solow, R. M. (1956). A contribution to the theory of economic growth.Quarterly Journal of Economics,70,65-94. http://www.jstor.org/Stable/1884513

Sunde,W., \& Vischer, T. (2012). Beyond balanced growth : The effect of human capital on economicgrowth reconsidered. In G. Mennill., Schlenzig, T., \& Friedrich E. (Ed.) Balanced Growth : FindingStrategies for Sustainable Development Management for Professionals, 14, 11-22.http://www.springer.com/978-3-642-24652-4

Torabi, F., \&Abbasi-Shavazi, M.J. (2015).Women's human capital and economic growth in the Middle East and North Africa. Journal of International Women's Studies, 16(3), 237-261.http://vc.bridgew.edu/jiws/vol16/iss3/16

Torruam, J. T., \& Abur, C. C. (2014). Public expenditure on human capital development as a strategy for economic growth in Nigeria: Application of co-integration and causality test analysis. International Journal of Research in Humanities and Social Studies, 1(2), 14-23

Tucker, L. R., Koopman, R. F., \& Linn, R. L. (1969).Evaluation of factor analytic research procedures by means of correlation matrices.Psychometrika, 34(4), 421-459. http://dx.doi.org/10.1007/BF02290601

UNDP. (2015). Human development reports (HDR). http://hdr.undp.org/en/composite/trends

Wawire, N. W., \&Nafukho, F. M. (2006).Investment in human capital through institutions of higher education for the revival of Kenya's economy, 56(2), 1184-1190. http://files.eric.ed.gov/fulltext/ED492815.pdf

Weiss, D. (1976). Multivariate Procedures. In: M.E. Dunnette (Ed.) Handbook of industrial/organizationalpsychology. Chicago, IL: Rand McNally.

Yong, A. G., \& Pearce, S. A. (2013). Beginner's guide to factor analysis: focusing on exploratory factor analysis. Tutorials in Quantitative Methods for Psychology, 9(2), 79-94.

\section{(cc) $\mathrm{BY}$}

This work is licensed under a Creative Commons Attribution 3.0 License. 